\title{
2018 Annual Report of Chinese Semiotic Studies
}

\author{
Haoyun Zhu \\ The College of Literature and Journalism, Sichuan University, Chengdu, \\ China \\ 674278257@qq.com \\ Guangxiang Rao \\ The College of Literature and Journalism, Sichuan University, Chengdu, \\ China \\ raoguangxiang@163.com
}

\begin{abstract}
By analysing semiotic papers, works and academic conferences from 2018, this paper aims to describe the development of Chinese semiotics. During this year, the study of semiotics in China further advanced in the fields of Marxist semiotics, communication semiotics, cultural semiotics, ecological semiotics and art semiotics. Overall, theoretical explorations and the integration of applications became development trends in semiotics. Further, the traditional concept of semiotics gained new interpretations through the introduction of new methods and ideas. In turn, the 'meaning' attribute of semiotics provided a unique analytical perspective for cutting-edge topics such as artificial intelligence and ecological environments.
\end{abstract}

\section{Keywords}

2018 semiotics - development process - communication semiotics - theory application fusion

Overall, in 2018 Chinese scholars' studies of semiotics made steady progress, intensifying theory exploration and expanding applications. Such progress is embodied in the following practices: the ongoing fusion of Western Marxist semiotics and traditional Chinese semiotics; the penetration of communication 
semiotics into media and journalism; a clearer definition of fundamental semiotic notions arising from constant contention; and initial breakthroughs made in pioneering subjects such as technical semiotics and ecological semiotics with the backing of new technologies. This paper inventories the academic activities and domestically published papers and monographs. Based on this inventory, it conducts a retrospective review of the development trajectory of Chinese semiotics in 2018.

An Overview of the Development Trajectory of Chinese Semiotics in 2018

\subsection{Publication of Papers}

In 2018 , the number of papers published on www.cnki.net with the theme 'symbol', or that incorporated the keyword 'semiotics', totaled 1,225. The number of these papers devoted to 'journalism and communication' increased from 88 to 115 , accounting for the largest proportion of semiotic studies, indicating the popularity of this subject area in academic circles. Meanwhile, the number of papers devoted to 'fine arts', linguistics', 'film and television', and 'literature' was almost the same as last year, meaning that these papers on traditional topics have maintained their popularity. Beyond these areas, attention has been paid to subjects including 'building science', 'urban and rural planning', 'philosophy', 'market economy' and 'commercial economy'. The application of semiotics to geography, economics and philosophy merits further study.

\subsection{Information about Academic Activities}

The year 2018 was fruitful, highlighting achievements in semiotics-related academic activities. In terms of themes, semiotics activities were closely related to fields including communications, linguistics, literature and art, and Marxism. In terms of scale, these activities were often larger and had a more profound impact on follow-up research than in previous years.

In 2018, semiotic activities retained their cultural momentum. The progress made in this field was represented at the 'International Conference on the Construction of a Literary Criticism Value System and Cultural Semiotics' held at Nankai University in Tianjin from 16 to 17 June. The conference was initiated under the auspices of the School of Literature, Nankai University, the Institute of Semiotics and Media Studies, Sichuan University, and the Shanghai Journal of Exploration and Free Views. Hundreds of renowned scholars from China and abroad engaged in heated discussions on the 'mutual-learning 
and penetration of the literary criticism value system and cultural semiotics' (Zhu and Sun, 2018: 140-144). The outcomes of these discussions have been extremely important to accelerating the construction of a literary criticism value system in China.

Based on the real foundations of the media today, more and more studies have become dedicated to communication semiotics. The 'First Conference on the Association of Communication and Semiotic Studies and the 2018 Forum' was held at Sichuan University on 9 and 10 July, thanks to the support of academic communities such as the Committee on Communication and Semiotic Studies of the Chinese Association for the History of Journalism and Communication, and the Committee on Communication and Cultural Semiotic Studies of the China Association for Sino-foreign Literature and Art Theory. A total of 180 scholars were present at the conference, exchanging views on topics of great interest. These included the 'reflection and transcendence of communication studies', 'the semiotic path taken by semiotic studies', 'the development trends of communication and semiotic studies', 'the application of semiotic approaches in today's culture' and 'the new development directions of semiotics'. The exhaustive number of topics discussed, and the novelty of the perspectives adopted by the scholars demonstrated their devotion to semiotic studies. This was the concrete embodiment of communication and semiotics' integration with studies of ontology and methodology.

Linguistics serves as one of the foundations of modern semiotics. Against the backdrop of differentiated linguistic forms, the value of studies around linguistics has been fully uncovered. Both the 'Second Forum on China's Theoretical Linguistics: New Advances and Their Collaborations', held at Tianjin Foreign Studies University from 12 to 14 October, and the 'Thirteenth Conference of the Chinese Association for Language and Semiotic Studies' at Tongji University, Shanghai, from 19 to 21 October, were dedicated to hot topics such as semiotic theories, interdisciplinary semiotics, social semiotics, cognitive semiotics, cultural semiotics, signs and media, and semiotics and social practice. These meetings unveiled the current integration status of semiotics and linguistics in the era of new media.

From 28 to 30 December, the 'Second Forum on Marxist Semiotics' with the theme, 'Marxist Semiotics: Theoretical Framework and Frontier Issues', took place at Wuhan University. Scholars presenting at the forum discussed in detail how our life's purpose is written in signs, and how much leeway there is for self-development under such circumstances. The approaches they took to questions of Marxism varied greatly, depending on their different theoretical, linguistic, semiotic, and media perspectives. The successful conclusion of that 
forum helped draw the curtains on the year's grand academic union in the semiotics field.

Apart from the conferences, two advancements in scientific semiotics research this year deserve attention. The first was the formation of the Committee on Communication and Semiotic Studies of the Chinese Association for the History of Journalism and Communication on 21 April. Its establishment represented the official indication that semiotic studies have gained admittance into academic institutions. It also represented the strong expectations of the academic field, which is eager to see progress in scientific research related to communication and semiotic studies, in addition to bridging exchanges at home and abroad. The second was the semiotics-related topic, 'The Genealogy of "Bashu Symbols" and the Communication of Digital Humanities', which was granted special funding by the National Social Science Fund of China as a major research project on forgotten lore. The approval of that project has helped to preserve the traditional objects of Chinese writing and culture. It has unshackled the practice of academic research being dominated by alphabetic writing, and has gone a long way in constructing a unique system tailored to the current conditions of Chinese semiotics. All of these achievements suggest that semiotics, as an independent body of knowledge that was once unpopular, is again being spotlighted based on its extraordinary advances.

\subsection{Publications of Monographs}

A monograph, characterised by its systematic format and explanatory language, is a specialist work of writing on a single subject or an aspect of a subject. One can gauge the development stage of a subject's theories and framework based on the publication of monographs on that subject. In 2018 , there were 27 published monographs and translations relevant to semiotics. Among them, fewer works were devoted to analysing basic semiotic notions compared with prior years. However, the focus of the works was extensively expanded in two areas: 'bringing in' and 'going beyond'.

For 'bringing in', brand new theories have helped to support the theoretical framework of semiotics in a manner that is both cultural and profound. For example, L'obvie et l'obtus (second edition, 2018) translated by Huai Yu, and Structuralism and Semiotics (2018) translated by Fu Zhiqiang, perfected the logical grounding and framework of semiotics by building on the works of foreign masters in the field. A History of Chinese Image Culture: The Volume on Image of Characters (2018), co-edited by Zhu Yongming and Hu Tianxuan, and A Semiotic Approach to Art History and Contemporary Art (2018), by Duan Lian, endeavoured to provide a clear picture of semiotics from the perspective of diachronism. The Chinese version of A Cultural Semiotics of Religion (2018), 
by Wei Quanfeng, and Essays on National Semiotics (2018), complied by Zong Zheng, adopted an ethnic and religious perspective to probe deeply into semiotic theories. Apart from these works, a series of books on Chinese literature and anthropology compiled by Ye Shuxian touched on semiotics several times. For example, the reprinted Cultures and Symbol Economy (2018), Cultural Semiotics: A New Insight into Great Tradition and Small Tradition (2018), Cultures and Symbol Economy (2018), and Symbols, Language and Art (2018), analysed the mix and evolution of social lives from the perspectives of culture and the economy. As such, they are a testament to the applicability of semiotic theories from the macro perspective of social structures.

'Going beyond' the boundaries of subjects has provided more practical guidance on real issues. For instance, the Brand Semiotics (2018), by Wang Haibo, the Chinese version of Applied Semiotics (2018), by Wei Quanfeng et al., and Crossover Creativity (2018), by Ling Yu, have become new phenomena in the media field. Essays on the Meaning of Cinema (2018), translated by Cui Junyan, Drama: A Narrative Account of the Semiotics of Performance (2018), by Hu Yiwei, and The Body Language of Dance (2018), co-authored by Zhang Suqin and Liu Jian, analysed the texts of films and television programmes. Such books as The Representation and Practice of the Spatial Symbol of Religious Culture (2018), by Dong Lin, Criticism and Deconstruction: A Research on the Design Philosophy of 'Memphis' (2018), by Tang Lin, and Urban Consumer Practices in China: Symbolization and its Reasons (2018), by Zheng Zhen, focused on spatial and geographical conditions. A Text Analysis of the 'Red Sorghum' From the Perspective of Translation Semiotics (2018), by Pan Linlin, and the Identity Performance in Chinese American Literature (2018), by Xu Shuangru, were in-depth analyses of literary works.

In 2018, research into semiotic theories in China achieved remarkable progress, developing new hypotheses and abandoning old ones. Both the macro guidance of abstract theories and the nuances of minor concepts were examined. These achievements were reflected in three transformations: the accelerated localisation process of Marxist semiotics; the expansion of the research into communication semiotics; and the clarification and development of theories and concepts on semiotics.

Research into Marxist semiotics has continued to thrive, with the intrinsic logic between signs on the one hand, and cultures and economies on the other, as the main topics to study. As for works on writing, Key to the Literature and 
Art Theories of the Eastern European Neo-Marxism (2018) explored the impact of linguistics and semiotics' new focus on the literature and art theories of Eastern-European neo-Marxism. It concluded that only by factoring in the role played by semiotics and linguistics in theories of art and literature can the soundness of key thoughts on Eastern-European neo-Marxism be fully penetrated. Alternatively, Cultures and Symbol Economy (2018), Cultural Semiotics: A New Insight into Great Tradition and Small Tradition (2018) and Symbols, Language and Art (2018), all by Ye Shuxian, built on culture to show the process of transforming economic and cultural resources into productive forces. In this way, they revealed the developmental tracks of cultural and creative industries in modern society.

More than 30 papers devoted to an analysis of Marxist semiotics were published in various periodicals in 2018. In addition, such journals as Literary Review and Signs and Media opened-up fields such as 'the theories of literature and art of Marxism' and 'semiotics and aesthetics of the neo-Marxism of east Europe' for further research. Some scholars focused their academic interest on introducing the ideas of Western Marxism to aesthetics (Fu, 2018), consumption (Chen W., 2018; Ge, 2018; Huang, 2018) and culture (Yang, 2018) as a way of consolidating the theoretical foundations of semiotic studies of Marxism in China. Some scholars took a critical approach to dealing with real problems related to the localisation of Marxism (Kuang, 2018a; 2018b). In other works, Fu Qilin (2018) examined the impact of linguistics and semiotics' exchange of focus on literature and art theories of neo-Marxism in Eastern Europe in his book the Key to the Literature and Art Theories of the Eastern European Neo-Marxism (2018).

While bringing in Marxist semiotics, many scholars have been mindful of research on the semiotic approach implied by traditional Chinese cultural theories. For example, Su Zhi (2018) examined relevant theories in Western philosophy and cognitive linguistics in his book A Semiotic Approach to the I Ching, in which he attempted to interpret the semiotic logos in the hexagrams of the IChing by uncovering the sign system in this classic work. Zhu Dong and Cao Huimin (2018) also based their work on traditional Chinese culture. They conducted a comparative study of the rational thoughts of Chinese Daoism and the semiotic essence of Marxism as a way to promote harmony between man and nature. Li Weihua (2018) relied on both Western and Chinese theories to examine the bilateral interaction of theories and texts. In this way, he offered constructive ideas on methodology to promote the development of semiotics in classical Chinese literature.

Other academics have summarised the semiotic features found in the ritual theory of Confucianism, the legal thought of Daoism and the rational thought 
of Mohism and its School of Logicians (Zhu, 2018a; 2018b; 2018c; 2018d). By doing so, they have pointed out the legacy of Chinese semiotics, which has helped to facilitate academic exchanges between China and the rest of the world. Zhu Yongming and Hu Tianxuan (2018) viewed semiotic linguistics as the starting point, going on to discuss its beginning, composition and dissemination in their book A History of Chinese Image Culture: The Volume on Image of Characters. They took a more multifaceted and panoramic view to show the evolutionary trajectory of Chinese characters. Thus, the outcomes of traditional Chinese semiotics have been extremely important to promoting exchanges between the distinctive cultures of the East and the West, and to applying modern theories to analyses of traditional Chinese cultures.

In recent years, communication semiotics has become a hot topic. Several papers devoted to it have been published, with much-discussed findings. 'Communication' and 'media', the key words in communication semiotics, have continued to draw the attention of the academic world.

Ling Yu (2018) wrote her book Crossover Creativity in the post-modernist context of transdisciplinary views, and utilised the theories of semiotics, narratology and mesology to discuss the methods for integrating literature and art. Zhang Cheng (2018) affirmed the conative and phatic value of the term 'communication arts' by looking at the differences between such concepts as 'communication', 'medium', and 'media'. Li Jin (2018) approached this matter from the perspectives of 'meaning of information' and 'social interaction' to determine the overlaps between Foucault's theories and communication studies from three perspectives: medium technology, meaning and object of information. Jiang Xiaoli and Jia Ruiqi (2018a) analysed the semantic field in the post-communication era from the perspectives of the metalanguage system, arbitrariness, and motivation. Their findings have provided inspiring guidance for the dissemination of the web culture and mobilisation of gamification in communication.

Apart from the routine discussion of communication semiotics, research into news-games represented one of the highlights of 2018. First, Jiang Xiaoli and Jia Ruiqi (2018b) classified news-games from the perspective of semiotic narratives based on the parameters of 'nonfiction and fiction' and 'timeliness and tardiness'. Thereafter, they went on to ascertain whether there was a narrative property implied in current news-games and how far this property was from the perspectives of 'property' and 'degree' of narrativity. Subsequently, some scholars have followed this line of narrative to reflect on challenges to the recipients' free will in news-games from the perspective of symbolisation and remediation (Li, 2018). Against the backdrop of revolutionary news media technology, some academics have noted the criteria for judging the 
trustworthiness of news and have tapped into the conditions for 'eunomia' and 'anomie' through comparative studies from the semiotics perspective. They have concluded that 'anomie in news' arose when news attempts to produce marked information in a structuralist sense. (Rao \& Li, 2018).

As for research into the fundamental theories of semiotics, the works produced in 2018 were mainly devoted to the analysis and discussion of structuralism and logic. Chen Suyan and Zhang Xiurui (2018) co-translated a book entitled Symbolic Logic: Syntax, Semantics and Proof, which decided the usages and rules of propositional logic and predicate logic from the perspective of symbolic logic. The book concluded that propositional logic is decidable whereas predicate logic is undecidable (Agler, 2018). This finding offers practical guidance for the proposition, distinguishing and verifying symbolic logic. Structuralism and Semiotics, translated by Fu Zhiqiang, included the masterpieces of reputable structuralists who dissected the basic concepts of structuralism to show how structuralism and semiotics were formed. This has been useful to later scholars wanting to ascertain the origins of semiotics (Hawks, 2018).

In terms of the fruits of theoretical research, the papers produced in 2018 were mainly devoted to the discrimination and re-exposition of basic semiotic concepts. Zhao Yiheng (2018b) returned to the fundamental issue in semiotics, 'the absence of the interpretive meaning calls for signs' (Zhao, 2012: 46), and put forward the idea that symbols pre-existed meaning. He made a point of analysing the world of meaning. To reveal semiotic truth, Zhao (2018d) underlined the complementarity of Peirce's 'truth teleology' and Norbert Wiener's 'feedback teleology' by sorting out the development patterns of teleology. Wang Xinpeng and Wang Yongxiang (2018) contributed to the realisation of intertextuality and cross-textual truth from the perspective of philosophical semiotics by means of a cognitive gap. To decompose the two keywords 'myth' and 'symbol', Tang Xiaolin and Cheng Tianyue (2018) referred to Mythologies by Roland Barthes and concluded that 'myth could only be deconstructed by mythologising myth itself'. Kang Cheng (2018) discussed Yuri Lotman's 'symbol' and the Tartu-Moscow Semiotic School, helping to make the mechanism of meaning generation and cultural memory the core concepts of cultural semiotics.

The concepts of 'style', 'genre', 'emotion' and 'rhetoric' have appeared more frequently in papers devoted to studies of basic semiotic theories, representing a step-up in terms of research thoroughness. Zhao redefined the key concepts of 'style', 'genre', 'emotion' and 'rhetoric' (Zhao \& Lu, 2018), vindicating and verifying their redefined definitions from the three aspects of 'cold emotion, 
nil style and zero rhetoric' by referring to Barthes's book Writing Degree Zero (Zhao, 2018c).

Tan Guanghui held different views of the definitions of 'rhetoric', 'emotion' and 'style'. He regarded emotion as an additional factor to text content, style as an attached element to text forms and rhetoric as a somewhat intentional technique to overthrow the conventional practices used to express meanings (Tan, G.; He, \& Wang, 2018). Zhao Xingzhi and Peng Jia (2018) expounded on the relationship between emotion (as the emotional interpretant [Firstness]); style (as the energetic interpretant [Secondness]); and rhetoric (as the logic interpretant [Thirdness]). Zhao (2018) affirmed the profound significance of universal rhetoric initially put forward by Charles Sanders Peirce (CP 2: 105109). Zhao remarked on how scholars have engaged in compelling discussions, analysing in-depth how 'emotion, style and rhetoric' exist and function in a text. These theoretical fruits have provided readers with more accurate explanatory approaches to unravel the real semiotic and rhetoric problems.

\section{Studies on the Application of Semiotics Produced in 2018}

The clashing views of classical and modern culture; the contrasting presentations between the operational practices of science and technology and the originality revealed in art and literature; the close association between personal development and environmental change; and observations all fall within the scope of the semiotic world. With its distinct advantages, semiotics, as the common denominator in the field of humanistic and social sciences, can be used to interpret social cultures. As a result, in 2018, research into the application of semiotics continued to revolve around concrete 'practical' issues and followed with great concern the relationship of human-objectmeaning' from a descriptive or interpretive perspective.

From the beginning, academics have confirmed the guiding role of semiotic theories in the practical topics found in their works. The Chinese version of Applied Semiotics absorbed the strengths of the American and French schools and depicted the evolutionary path from the simplest 'encoding' to the most complex 'culture' by analysing the six elementary notions of 'encoding', 'symbol', 'discourse', 'action', 'text', and 'culture'. This shed a bright light on the application of semiotics (Larsen, 2018). Guided by semiotic theories, Brand Semiotics concentrated on symbol consumption in modern society, revealing the close association between symbols on the one hand and economy and culture on the other by sorting out the meaning and denotation of brand symbols, 
the establishment of symbolic meaning, the integrated propagation of brands and the consumption of brand symbols (Wang H., 2018). The Urban Consumer Practices in China: Symbolisation and Its Reasons, as a reference for eliciting rational consumption behaviours from domestic consumers, unveiled the semiotic mechanism underpinning urban mass consumption by combining the semiotic, questionnaire and interview approaches (Zheng, 2018).

In 2018, scholars concentrated on decomposing the paths for expressing meaning in concrete art forms in literature and art. For example, the Chinese version of Essays on the Meaning of Cinema made film a research object. It included a critical examination of and provided responses to the film theories that 'represent endings' and 'analyse psychologies' from the perspectives of phenomenology, linguistics, narratology, stylistics and semiotics (Metz, 2018). Drama: A Narrative Account of the Semiotics of Performance positioned drama as an object of study and explored it from the perspectives of genre, media, the accompanying text and narrative frame, abstracting the encoding and decoding process of drama performances (Hu, 2018). The Body Language of Dance made dance an object of study and discussed the relationship between 'body', 'language', and 'aesthetics' in dance from a biological view of body formation, a semiotic view of body expression, a philosophical view of body thoughts, and an artistic view of body representation (Zhang \& Liu, 2018). Significant Form: A Study on the Cultural Remains of Chinese 'Circle Dance' from the Perspective of Dance Semiotics shared the same subject ('dance') with Zhang and Liu's work. Resorting to the relevant ideas of symbolism, semiotics, and morphology, it concluded that 'circle dance' appears as the 'most concentrated reflection of the lives, emotions, beliefs and even the social and organisational relations in the early times' (Hai, 2018: 4-15).

In the fields of culture and religion, scholarship highlighted the influence of signs on the structure of culture by extracting their symbolic representations. The Chinese version of $A$ Cultural Semiotics of Religion gauged the sustainability and unsustainability of religions from a cultural perspective by showing the related semiotic concepts (such as symbol-text-culture, symbolic philosophy, and cultural philosophy) (Leone, 2018). The Representation and Practice of the Spatial Symbol of Religious Culture, unfolding the sequence of religious viewpoints, perceptual morphology, essential properties, and the praxis model, provided a systematic introduction to the cultural symbols and representations peculiar to the 'space of religious culture' (Dong, 2018). Essays on National Semiotics relied on semiotic theories to analyse national semiotics from the perspective of cultural semiotics, and finished building the cultural system-language simulator system (Zong, 2018). 
Among the papers published in 2018, biosemiotics, artificial intelligence, and network technology appeared as research focuses based on their conformation to social development trends. Studies of space and landscapes centred on geographical conditions stood out from other topics. Research on conventional subjects such as language, literature, art, advertising, and consumption remain underway.

In terms of the relations between human and biology, and human and machines, and based on the premises that human functions as a species, some academics re-conceptualised biology with Peircean semiotics by redefining facts, problems and methods of biology. They treated life processes as meaning-making, informational processes rather than mechanical ones (Zhou, 2018). Some scholars delved into the role that language plays in establishing and mapping human beings' species-specific Umwelt by tracing it back to the principles of Dao and Ming (Naming) in Laozi (Han, 2018). In discussions on artificial intelligence (AI), some scholars resorted to Peirce's semiotics which, on the one hand, indicate that human thinking is creative, and on the other hand, reflect the division between humans and machines by claiming that man has a high-level of self-control that machines lack (Chen X., 2018). Some scholars argued that human feelings can be totally digitalised, judging from the emotions themselves, and deemed that AI and emotion simulators can magnify the rational part of human thought, but can never imitate or become a substitute for the human senses (Tan G., 2018). So far, building on its own endowed traits, semiotics has offered professional viewpoints on the core issues surrounding AI.

In the field of the geographical environment, ecosemiotics, and the development of tourism resources drew wide attention. Some scholars approached this matter from the symbol consumption perspective. This resulted in micro- and macro-level revelations on the green development of the Chinese nation and an ecological civilisation by delving into the real ecological crises caused by excessive symbol consumption (Ji \& Zhu, 2018). Some scholars pondered the relationship between the development of tourism symbols and the ecological culture, asserting that tourism consumption symbols are 'spectacled' (Li, 2018). Some scholars explored this topic from the perspective of tourist semiotic practices. They acknowledged the significance of tourist semiotic practices and how they drive the subjective transformation of tourist attractions and the objective evolvement of tourist elements from four aspects: materials, competences, meanings, and tourists (Chen G., 2018). Some scholars investigated tourism and probed the processes of social relationship creation and material production incorporated into the production of space from the 
dimensions of 'spatial practices', 'spatial representation', and 'the space of representation' (Tan H. \& Zheng, 2018).

The number of papers devoted to the study of 'space' and 'place' grew markedly in 2018, with some novel ideas appearing. Some scholars treated cities as relational spaces and established communications between special urban buildings and the spaces through symbol occupation (Jiang H., 2018). Others positioned leisure sports in urban space as an object of study, and 're-skinned' the urban space. According to them, these sports release the dialectical tension between body movement, symbolism, and the physical body through perception, imagination, and reality (Zhang Z., 2018).

In 2018, the fruits of research continued to be reaped in the fields of language, literature, art, and images. In-depth studies of translation semiotics theories were conducted in the realm of linguistics. Some scholars approached the semiotic equation from the perspective of semiotic universals, the law of conservation of information, and constant information of the text (Tong \& Wang M., 2018). With a theoretical foundation based on Peirce's trichotomy of signs, others constructed a text-interpretation mode of translation semiotics in terms of the mechanism of translation semiosis, the reasoning model, and the translation types of translation semiotics (Pan, 2018). Some scholars reviewed Peirce's studies of 'beliefs', highly praising the universality, objectivity, and absoluteness of translation semiotics (Jia, 2018).

In the realm of art, research findings resulted from the in-depth analysis of its definition and properties and further interpretation of 'artifying'. Symbols, Language and Art and A Semiotic Approach to Art History and Contemporary Art pondered the origin, development process and evolutionary rules of pre-historic art from the perspective of semiotics, unveiling the evolution of artistic thought in terms of diachronism (Duan, 2018; Ye, 2018). Some scholars proved by contradiction that 'art as a presenting sign' is inapplicable. Art as a revealed 'presenting sign' is thus justified (Zhao K., 2018). Other scholars conducted comparative studies of the pros and cons of structuralism and functionalism in an effort to advance the definition of art. They aimed to reveal the adjustment to art's 'breakaway from objects' and expand the possibilities for the infinite semiosis of the interpretant (Zhao Y., 2018).

In the field of visual images, web emoticon turned out to be a new hot spot in pictorial semiotic studies. Some scholars argued that web emoticon uses the multimodal form of 'graphic-structure' and rhetorical devices like metaphors and intertextuality to bring about the exchange of feelings and aggregation of cultures in an 'integrated whole of image behaviour' 
( $\mathrm{Qu} \& \mathrm{Li}, 2018$ ). Some scholars asserted that web emoticons construct a field of communication through bodily representation and emotional saturation, enabling emoticon users to build funny images (Rao \& Wei, 2018). Apart from the above-mentioned studies, the visual shift in music was also investigated. Some scholars construed the transformational process of music from auditory symbol coding to multi-media symbol coding from the perspective of $\mathrm{MV}$, multi-media and music festivals (Lu \& Wei, 2018).

Taking a retrospective review of Chinese semiotic studies, it could be argued that the semiotic studies of 2018 showed more concern for reality. Many research findings were positive responses to the theoretical and practical problems that have emerged from the current development process of Chinese semiotics.

In the realm of basic theories, academics introduced Western Marxist semiotics to construct a theoretical framework of modern semiotic studies. They also based their research on the realities of Chinese semiotics to draw out the developmental trajectory. They argued about the core concepts of semiotics, which helped to crystallise these concepts and supplement them with key content, reinforcing the theoretical cornerstones of semiotics. As a result, classic semiotic theories have once again begun to shine with fresh meanings. After much discussion, the research from 2018 has been a step-up from previous years.

New research topics have been added to the overall research spectrum, contributing to its ever-expanding frontier. Communication semiotics has turned out to be the development priority in recent years, and the choice of which objects to study has catered more to the current conditions of communication and the media. The semiotic studies of 2018 explored such topics as AI, ecology, and environmental problems, suggesting that semiotics has gone beyond the individual beings of 'human' in the world of meaning into a holistic discussion over the relationship between man and technology, and man and the environment. This broadened vision has greatly promoted the establishment of a systematic perspective of semiotic thought.

In 2018, Chinese semiotic studies made a great leap forward. However, scholars should continue to be alert to such problems as the unbalanced efforts devoted to each research topic and the blind use of semiotic theories. They should also take the initiative to tackle these problems. This paper illustrates the development of semiotics in 2018 , and vigorously reiterates the feasibility of semiotics. Yet, straitened by time and energy limitations, this paper is far from complete. Please contact the authors to discuss any omissions. 


\section{References}

Agler, David W. (2018). Symbolic Logic: Syntax, Semantics and Proof (Chen Suyan et al., trans.), Beijing: Science Press.

An, Jing (2018). 'A Study into the Essense of Chinese Aesthetics from the Perspective of the Art Semiotics of “Cultivation of People through Poetry"' (从 “诗教” 的艺 术符号学阐释看中华美学的生命精神, Cong shi jiao de yi shu fu hao xue chan shi kan zhong hua mei xue de sheng ming jing shen). Journal of Southwest University for Nationalities (Humanities and Social Sciences) 39(o2): 169-177.

Chen, Gang (2018). 'The Conceptual Framework and Dynamic Analysis of Tourist Semiotic Practice' (旅游者符号实践的概念框架及其动态分析, Lu you zhe fu hao shi jian de gai nian kuangjia ji qi dong taifen xi). Tourism Tribune (11): 66-74.

Chen, Wenbin (2018) 'Returning to Marxism: Refutation of Baudrillard's Interpretaion to the Consumer Society' (重回马克思: 反驳鲍德里亚对消费社会的解读, Chong hui ma ke si fan bo bao de li ya dui xiao fei she hui de jie du). Journal of Lanzhou University (Social Sciences) 46(o3): 167-172.

Chen, Xi (2018) 'Peirce's Semiotics and Its Inspiration to the Development of AI' (皮尔士符号学及其对人工智能发展的启示, Pi er shi fu hao xue ji qi dui ren gong zhi neng fa zhan de qi shi). Journal of Dalian University of Technology (Social Sciences) 39(o6): 107-111.

Dong, Lin (2018) The Representation and Practice of the Spatial Symbol of Religious Culture (宗教文化的空间符号表征与实践, Zong jiao wen hua de kong jian fu hao biao zheng yu shijian). Beijing: Social Sciences Academic Press.

Duan, Lian (2018) A Semiotic Approach to Art History and Contemporary Art (从艺术史 到当代艺术的符号学研究, Congyi shu shi dao dang dai yi shu de fu hao xue yan jiu). Nanjing: Phoenix Fine Arts Publishing House.

Feng, Yueji (2018) 'Cognitive Communication: Questions about its Discipline Legitimacy’ (认知传播学: 学科合法性质疑, Ren zhi chuan bo xue xue ke he faxing zhiyi). Editorial Friend(o7): 31-36.

$\mathrm{Fu}$, Qilin (2018) 'Theoretical Form of Marxism Aesthetics in Eastern Europe and its Reference Significance to China' (东欧马克思主义美学的理论形态及其启示, Dong ou ma ke si zhu yi mei xue de li lun xing tai ji qi qi shi). Literary Review (o1): 30-36.

Fu, Qilin (2018) Key to the Literature and Art Theories of the Eastern European Neo-Marxism (东欧新马克思主义文艺理论的核心问题, Dong ou xin ma ke si zhu yi wen yi li lun de he xin wen ti). Beijing: China Social Sciences Press.

Ge, Zaibo (2018) “Commodity-Sign” Mode: A Review of Jean Baudrillard's Thought on Advertising and Consumer Society’ (“商品-符号” 论:鲍德里亚消费社会思想 评析, Shang pin fu hao lun bao de li ya xiao fei she hui si xiang ping xi). Journal of Lingnan Normal University 39(04): 155-16o. 
Gibson, Clare (2018) How to Read Symbols: A Crash Course in the Meaning of Symbols in Art (Zhang Wenshuo, Trans). Shenyang: Liaoning Science and Technology Publishing House.

Hai, Weiqing (2018) Significant Form: A Study on the Cultural Remains of Chinese 'Circle Dance' from the Perspective of Dance Semiotics (有意味的形式舞蹈符号视角下的中 华 ‘圈舞” 舞蹈文化遗存研究, You yi wei de xing shi wu dao fu hao shi jiao xia de zhong hua quan wu wu dao wen hua yi cun yan jiu). Chengdu: Sichuan University Press.

Hai, Weiqing. (2018). Meaningful Forms: A Study of the Culture of Chinese 'Circle Dance' from the Pespective of the Semiotics of Dancing (有意味的形式:舞蹈符号视角下的 中华 “圈舞” 舞蹈文化遗存研究, You yiwei de xingshi wudao fuhaoxue shijiao xia de zhonghua quanwu wudao wenhua yicun yanjiu). Chengdu, China: Sichuan University Press.

Han, Lei (2018) 'A Biosemiotic View of the Human Species-specific Umwelt in Laozi' (论《老子》的人类主体世界建构:一个生物符号学观点, Lun lao zi de ren lei zhu ti shi jie jian gou yi ge sheng wu fu hao xue guan dian). Signs \& Media (O2): 47-58.

Hawks, Terence (2018) Structuralism and Semiotics (Fu Zhiqiang, Trans). Beijing: Intellectual Property Publishing House.

Hu, Yiwei (2018) Drama: A Narrative Account of the Semiotics of Performance (戏剧: 演 出的符号叙述学, Xi ju yan chu de fu hao xu shu xue). Chengdu: Sichuan University Press.

Huang, Zhaoqiong (2018) 'Three Paths to Repudate the Consumer Politics of Western Marxism' (西方马克思主义消费政治批判的三种路径, Xifang ma ke sizhuyixiaofei zheng zhi pi pan de san zhong lu jing). Journal of Zhengzhou Institute of Aeronautical Industry Management (Social Sciences) 37(04): 46-54.

Ji, Zhipeng \& Zhu Zedong (2018) 'Criticism and Revealation: The Ecological Predicament and Green Development of Symbol Consumption' (批判与启示: 符号 消费的生态困境及绿色发展, Pi pan yu qi shi fu hao xiao fei de sheng tai kun jing ji $l v$ se fa zhan). Journal of Yunnan Administration College 20(o1): 109-115.

Jia, Hongwei (2018) 'On Defining the Beliefs of Translation Semiotics' (翻译符号学 的信念界定问题, Fan yi fu hao xue de xin nian jie ding wen ti). Journal of Yanshan University (Philosophy and Social Science Edition) 19(04): 6o-65.

Jiang, Hai (2018) 'Activating Space: A Study on the Formation Machenism of the Driving Forces of Urban Communication' (激活空间: 城市传播中的动力机制形成 研究, Ji huo kong jian cheng shi chuan bo zhong de dong li ji zhi xing cheng yan jiu). Journal of Southwest University for Nationalities (Humanities and Social Sciences) 39(11): 149-155.

Jiang, Xiaoli \& Jia Ruiqi (2018a) 'Gamification and Its Representation of Communication in the Post-Internet Era - From the Perspective of Semiotics' (后互联网时代的 
传播游戏化及其表征 - 一种符号学视角, Hou hu lian wang shi dai de chuan bo you xi hua ji qi biao zheng yi zhong fu hao xue shi jiao). Social Science Front (o1):149-156. Jiang, Xiaoli \& Jia Ruiqi (2018b) 'News-game: On Defining One Property' (新闻游戏: 一个属性的界定, Xin wen you xi yi ge shu xing de jie ding). Press Circles (01): 42-47.

Jiang, Xiaoli \& Jia Ruiqi (2018c). 'Nonfictional Narrative Research into News-games', (新闻游戏的非虚构叙事研究, Xin wen you xi de fei xu gou xu shi yan jiu). Modern Communication 40(07): 70-74+81.

Kang, Cheng (2018). “'Symbol” in Cultural Semiotics', (文化符号学中的 “象征”, Wen hua fu hao xue zhong de xiang zheng). Foreign Literatures (o1): 1-8+156.

Kuang, Cunjiu \& Fu Qilin (2018). 'The Turn of Marxist Semiotics in Czechoslovakia', (捷克斯洛伐克的马克思主义符号学转向, Jie ke si luo fa ke de ma ke si zhu yi fu hao xue zhuan xiang).Jiangxi Social Sciences 38(o1): 24-31.

Kuang, Cunjiu (2018a). 'Acceptance of Eastern European Marxist Semiotics in China', (东欧马克思主义符号学在中国的接受, Dong ou ma ke si zhu yifu hao xue zai zhong guo de jie shou). Signs \& Media (01): 70-83.

Kuang, Cunjiu (2018b). 'Problems Occurred in the Localization of Western Marxist Semiotics', (西方马克思主义符号学本土化的若干问题, Xi fang ma ke si zhu yi fu hao xue ben tu hua de ruo gan wen ti). Academic Forum (o1): 16-22.

Larsen, Svend E. (2018). Applied Semiotics (Wei Quanfeng, Trans), Chengdu: Sichuan University Press.

Leone, Massimo (2018). A Cultural Semiotics of Religion (Wei Quanfeng, Trans). Chengdu: Sichuan University Press.

Li, Jin (2018). 'Foucault in the Perspective of Communication Semiotics: Social Interaction and the Meaning of Information', (传播符号学视角中的福柯 - 社会互动与讯 息意义, Chuan bo fu hao xue shi jiao zhong de fu ke she hui hu dong yu xun xi yi yi). Journal of Shanghai University (Social Science Edition) 35(o2):121-129.

Li, Junxin (2018). 'News-game and Its Moral Reflection from the Perspective of General Narratology', (符号叙述学视角下的新闻游戏及其伦理反思, Fu hao xu shu xue shi jiao xia de xin wen you xi ji qi lun lifan si). Press Circles (o9): 34-40.

Li, Weihua (2018). 'Chinese Classical Literature Semiotics: Objects, Strategies, and Methods', (中国古典文学符号学: 研究对象、策略及方法, Zhong guo gu dian wen xue fu hao xue yan jiu dui xiang ce lue ji fang fa). Journal of North China University of Technology, 3о(о3): 84-91.

Li, Yan (2018). 'Capital Logic, Symbol Consumption and Ecological Civilization Jianghan Tribune', (资本逻辑、符号式消费与生态文明, Zi ben luo ji fu hao shi xiao fei yu sheng tai wen ming).Jianghan Tribune (10): 63-69.

Lin, Shengdong, Paul Van Den Hoven, \& Zhang Yiqiong (2018). 'Global Adervitising Adaptation for Chinese Consumers in the Early 2oth Century: A Semiotic Approach'. Signs \& Media (01): 84-107. 
Ling, Yu (2018). Crossover Creativity (跨界网, Kua jie wang). Beijing: China Social Sciences Press.

Lu, Zhenglan \& Wei Yunjie (2018). 'The Visual Shift of Music in the New Media Environment', (新媒介环境下的音乐视觉转向, Xin mei jei huan jing xia de yin yue shi jue zhuan xiang). Academic Journal of Zhongzhou (10): 143-147.

Ma, Dakang (2018). 'Analysis of Cultural Genes: Based on the Structure of Symbolic System', (从符号系统结构探析 ‘文化基因', Cong fu hao xi tong jie gou tan xi wen hua ji yin). Journal of Social Sciences (04): 163-172.

Metz, Christian (2018). Essays on the Meaning of Cinema (Cui Junyan, Trans). Beijing: The Commercial Press.

Pan, Linlin (2018). 'The Text-Interpretation Mode of Translation Semiotics', (翻译符号 学的文本阐释模式, Fanyifu hao xue dewen ben chan shi mo xing). Foreign Language and Literature 34(03): 119-127.

Pan, Linlin (2018). A Text Analysis of the 'Red Sorghum' - From the Perspective of Translation Semiotics, (翻译符号学视阈下的《红高粱》文本阐释, Fan yifu hao xue shiyu xia de hong hao liang wen ben chan shi). Suzhou: Suzhou University Press.

Peirce, Charles Sanders. (1931-1958). Collected Papers of Charles Sander Peirce, 8 vols. Ed., Charles Hartshorne, Paul Weiss, and Arthur Burks. Cambridge: Harvard University Press.

Qu, Jirong \& Li Yiping (2018). 'Image Behavior as the Metaphor of "Social Emotion": The Symbols, Rhetoric and Discourse of Meme Emoticons', (作为 “图像行为” 的表 情包: 符号、修辞与话语, Zuo wei tu xiang xing wei de biao qing bao fu hao xiu ci yu hua yu). Editorial Friend (10): 45-50.

Rao, Guangxiang \& Li Jinhao (2018). 'Eunomia and Anomie: The Pursuit of the Marked of News Truth', (范与失范: 新闻真实的异项追求, Fan yu shi fan xin wen zhen shi de yi xiang zhui qiu). Press Circles (o6): 18-24.

Rao, Guangxiang \& Wei Qinglu (2018). "Interesting Me" and Superficiality: The Spread and Reflections of Web Emoticons', (“趣我”与浅平化: 网络表情符号的传播与反思, Qu wo yu qian ping hua wang luo biao qing fu hao de chuan bo yu fan si). Journal of Fujian Normal University (Philosophy and Social Science Edition) (o2): 161-168+172.

Roland, Barthes (2018). L'obvie et l'obtus (Huai Yu, Trans), Beijing, China: Renmin University Press.

Su, Zhi (2018). A Semiotic Approach to the IChing, (《周易》的符号学研究, Zhouyi de fu hao xue yan jiu). Chengdu: Sichuan University Press.

Tan, Guanghui (2018). 'A Semiotic Study on Inter-emotionality', (情感间性的符号学 研究, Qing gan jian xing de fu hao xue yan jiu). Signs \& Media (o2): 138-15o.

Tan, Guanghui, He Qian \& Wang Jiashen (2018). 'Reviews on “Emotion Study, Stylistics and Rhetoric: Discussion of Their Overlapping and Distinction”, (情感研究、风格 学、修辞学: 关于三者的重叠与区分的讨论” 综述, Qing gan yan jiufeng ge xue xiu 
ci xue guan yu san zhe de chong die yu qu fen de tao lun).Journal of Huaiyin Teachers College (Social Sciences Edition) 40(04): 382-386.

Tan, Hua \& Zheng Qiao (2018). 'A Study on Transplanting and Communication of Local Folk Culture from the Perspective of Space Production - A Case Study of Enshi Tujia Girl's Town', (空间生产视角下地方民俗文化的移植与传播 - 以恩施土家女儿 城为例, Kong jian sheng chan shi jiao xia di fang min su wen hua de yi zhi yu chuan bo yi en shi tu jia nv er cheng wei li). Journal of Hubei University for Nationalities (Philosophy and Social Sciences) 36(05): 71-75.

Tang, Lin (2018). Criticism and Deconstruction: A Research on the Design Philosophy of Memphis, (批判与解构孟菲斯设计思想研究, Pi pan yu jie gou meifei si she ji sixiang yan jiu). Beijing, China: Commercial Publishing House.

Tang, Xiaolin \& Cheng Tianyue (2018). 'The Alchemy of Mass Media and Ideologies Redefining Semiologist Roland Barthes' Mythologies', (大众媒介与意识形态的 炼金术 - 重审符号学家巴尔特的神话理论, Da zhong mei jie yuyi shixing tai de lian jin shu chong shen fu hao xue jia ba er te de shen hua li lun). Fujian Tribune (The Humanities \& Social Sciences Monthly) (o1): 110-117.

Tong, Yin \& Wang Mingyu (2018). 'On Semiotic Information Conservation from the Perspective of Translation Semiotics', (翻译符号学视域下的符号守恒, Fan yi fu hao xue shi yu xia de fu hao shou heng).Journal of Shandong Foreign Languages Teaching 39(o1): 99-110.

Wang, Haibo (2018). Brand Semiotics, (品牌符号学, Pin pai fu hao xue). Changchun: Northeast Normal University Press.

Wang, Jin (2018). A Study into the Cultural Analysis of the Literary Theorist 'Mieke Bal' in Contemporary Nerthelands, (当代荷兰文论家米克・巴尔的文化分析思想研究, Dang dai he lan wen lun jia mi ke ba er de wen hua fen xi si xiang yan jiu). Nanjing: Nangjing University Press.

Wang, Xinpeng \& Wang Yongxiang (2018). 'Cognition Gap and Truth: A Perspective of Philosophical Semiotics', (哲学符号学视域下的认知差和真知, Zhe xue fu hao xue shi yu xia de ren zhi cha he zhen zhi). Journal of Yanshan University (Philosophy and Social Edition) 19(04): 54-59.

Wu, Huifan (2018). 'Signification and Narrative: A Semiotic Approach to Urban Culture Communication', (表意与叙事: 城市文化传播的符号学解读, Biao yi yu xu shi cheng shiwen hua chuan bo de fu hao xue jie du). Contemporary Communication (o3), 31-34. $\mathrm{Xu}$, Shuangru (2018). Identity Performance in Chinese American Literature, (华裔美国文 学 “身份表演” 书写研究, Huayi mei guo wen xue shen fen biao yan shuxie yan jiu). Guangzhou: JiNan University Press.

Yang, Jiangang (2018). 'Seeking the Tension and Transcendence between Marxism and Semiotics - Based on Stuart Hall's Standpoint and Approach of Cultural Analysis', (寻找马克思主义与符号学的张力及其超越 - 斯图尔特 - 霍尔文化研究 
的立场与方法, Xun zhao ma ke si zhu yi yu fu hao xue de zhang li ji qi chao yue si tu er te huo erwen hua yan jiu de li changyu fang fa). Study \& Exploration (o9):138-145.

Ye, Shuxian (2018). Cultures and SymbolEconomy, (文化与符号经济, Wen huayu fu hao jing ji). Xi'an: Shaanxi Normal University Press.

Ye, Shuxian, Zhang Mili \& Liu Qianyue (2018). Cultural Semiotics: A New Insight into Great Tradition and Small Tradition, (文化符号学: 大小传统新视野, Wen hua fu hao xue da xiao chuan tong xin shi ye). Xi'an: Shaanxi Normal University General Publishing House.

Yu, Jianzhang \& Ye, Shuxian (2018). Symbols, Language and Art, (符号、语言与艺术, Fu hao yu yan yu yi shu). Xi'an: Shaanxi Normal University Press.

Zhang, Cheng (2018). 'On the Nomination of "Communication Arts" from the Perspective of Semiotics - Identifying the Differences of Communication, Medium and Media Arts', (符号学视角论 “传媒艺术” 的命名 - 兼辨 “传媒/媒介/媒体艺术” 之异, Fu hao xue shijiao lun chuan mei yi shu de ming min jian bian chuan mei mei jie mei tiyi shu zhiyi). Modern Communication 40(o9): 108-112+132.

Zhang, Jing (2018). Body of Pleasure: The Thoughts of Roland Barthes during His Last Decade, (欢愉的身体: 罗兰 - 巴特后十年思想研究, Huan yu de shen ti luo lan ba te hou shi nian si xiang yan jiu). Beijing: People's Publishing House.

Zhang, Suqin \& Liu jian (2018). Body Language of Dance, (舞蹈身体语言学, Wu dao shen ti yu yan xue). Beijing: Capital Normal University Press.

Zhang, Zhen (2018). 'The Inner Transcendence of Leisure Sports to the Alienation of Urban Space - Based on the Exploration of Lefebvre's Space Philosophy', (休闲体 育对城市空间异化的内在超越 - 基于列斐伏尔空间哲学的探赜, Xiu xian ti yu dui cheng shi kong jian yi hua de nei zai chao yue ji yu lie fei fu er kong jian zhe xue de tan ze). Journal of Chengdu Sport University (05):54-59.

Zhao, Kuiying (2018). 'Analysis on Arts as a Presenting Sign', (试论艺术作为出场符号, Shi lun yi shu zuo wei chu chang fu hao). Literary Review (04): 188-196.

Zhao, Xingzhi \& Peng Jia (2018). 'On Style, Emotion and Rhetoric: From Peirce an Trichology of Interpretant', (论风格与情感、修辞之关系:一个皮尔斯解释项三分 路径, Lun feng ge yu qing gan xiu ci zhi guan xi yi ge pi er si jie shi xiang san fen lu jing). Academics (o1): 105-112+286.

Zhao, Xingzhi (2018). 'Inquiry and Rhetoric: On Rhetoric in Peircean Semiotics', (探究 与修辞: 论皮尔斯符号学中的修辞问题, Tan jiu yu xiu ci lun pi er si fu hao xue zhong de xiu ciwen ti). Inner Mongolia Social Sciences (Chinese Version) 39(o1): 166-172.

Zhao, Yiheng. (2012). Semiotics: Principles and Problems, (符号学: 原理与推演, Fu haoxue yuanliyu tuiyan). Nanjing, China: Nanjing University Press.

Zhao, Yiheng \& Lu Zhenglan (2018). 'Style, Genre, Emotion and Rhetoric: Disentangled Through Semiotics', (风格、文体、情感、修辞: 用符号学解开几个纠缠, Feng ge wen ti qing gan xiu ciyong fu hao xue jie kaijigejiu chan). Academics (o1): 87-95+285. 
Zhao, Yiheng (2018a). 'Conceptulizing Art from the Perspective of Semiotics: Back to Funtionalism', (从符号学定义艺术: 重返功能主义, Cong fu hao xue ding yi yi shu chong fan gong neng zhuyi). Contemporary Literary Criticism (o1), 4-16.

Zhao, Yiheng (2018b). 'The First Paradox in Semiotics:The Absence of the Interpretive Meaning Calls for Signs', (符号学第一悖论: 解释意义不在场才需要符号, Fu hao xue di yi bei lun jie shiyiyi bu zai chang cai xu yao fu hao). Journal of Xihua University (Philosophy \& Social Sciences), 37(02): 1-5+11.

Zhao, Yiheng (2018c). ‘Cold Emotion? Nil Style? Zero Rhetoric? - A Semiotic Approach to Barthes's “Writing Degree Zero”, (冷感情?无风格?零修辞? - 关于巴尔特 “零度 写作” 的符号学论证, Leng gan qing wu feng ge ling xiu ci guan yu ba er te ling du xie zuo de fu hao xue lun zheng). Inner Mongolia Social Sciences (Chinese Version) 39(o1): 140-144+142.

Zhao, Yiheng (2018d). 'Peirce's “Truth Teleology” and Norbert Wiener's "Feedback Teleology”', (皮尔斯 “真知目的论” 与维纳” 反馈目的论”, Pi er si zhen zhi mu di lun yu wei na fan kui mu di lun).Journal of Fujian Normal University (Philosophy and Social Science Edition) (02), 145-153.

Zheng, Zhen (2018). The Urban Consumer Practices in China: Symbolization and Its Reasons, (中国都市中的消费实践: 符号化及其根源, Zhong guo du shizhong dexiao fei shi jian fu hao hua ji qi gen yuan). Beijing: Social Sciences Academic Press.

Zhou, Liqian (2018). 'Biosemiotics as an Alternative Paradigm for Biology: A Rational Reconstruction of the History of Biosemiotics'. Signs \& Media (o2):59-76.

Zhu, Dong \& Cao Huimin (2018). 'The Rational Spirit of Taoist Language View: A Comparison of Taoism and Marxist Cultural Semiotic Thoughts', (道家语言观的理 性精神: 道家与马克思主义文化符号思想的比较, Dao jia yu yan guan de lixing jing shen dao jia yu ma ke si zhu yi wen hua fu hao sixiang de bi jiao). Signs \& Media (o2): 93-103.

Zhu, Dong (2018a). 'From Xingming Xue to Semiotics: A Screening and Reflection of the Academic History', (从形名学到符号学: 一个学术史的梳理与反思, Cong xing ming xue dao fu hao xue yi ge xue shu shi de shu li yu fan si). Journal of North China University of Technology 30(о3): 92-98.

Zhu, Dong (2018b). 'Name and Rite: An analysis of the Semiotic Thought of Confucian School and Its Deeper Ideology', (名与礼: 儒家符号思想及其深层意识形态分析, Ming yu li ru jia fu hao si xiang ji qi shen ceng yi shixing tai fen xi).Journal of Lanzhou University (Social Sciences) 46(03):151-157.

Zhu, Dong (2018c). 'The Concept of Wen and Zhi: The Ethical Semiotic Dimension of Chinese Literary Criticism, (文质论: 中国文学批评的伦理符号学向度, Wen zhi lun zhong guo wen xue pi ping de lun li fu hao xue xiang du). Lanzhou Academic Journal (11): 40-49. 
Zhu, Dong (2018d). 'The Pre-Qin Social Order Semiotic Construction - Daoist Concept of Nature and Its Practice', (先秦社会秩序的符号建构 - 以道家的自然观及其 实践为考察对象, Xian qin she hui zhi xu de fu hao jian gou yi dao jia de zi ran guan ji qi shi jian wei kao cha dui xiang). Inner Mongolia Social Sciences (Chinese Version) 39(o1): 153-159.

Zhu, Lin and Sun, Mingyang. (2018). 'Review of the International Conference on "The Construction of the System of Values for the Literary Critics and the Semiotics of Culture”, (“文艺评论价值体系建设与文化符号学” 国际学术研讨会综述, “Wenyi pinglun jiazhitixi jianshe yu wenhua fuhaoxue guoji xueshu yantaohui zongshu'). Literature and Culture, 2018 (3): 140-144.

Zhu, Yongming \& Hu Tianxuan (2018). A History of Chinese Image Culture: The Volume on Image of Characters, (中华图像文化史: 文字图像卷, Zhong hua tuxiang wen hua shiwen zi tu xiang juan). Beijing: China Photography Press.

Zong Zheng (2018). Essays on National Semiotics, (民族符号学论文集, Min zu fu hao xue lun wen ji). Beijing: China Social Sciences Press. 